Smolders, M., Laurant, M., Rijswijk, E. van, Mulder, J., Braspenning, J., Verhaak, P., Wensing, M., Grol, R. Depressed and a co-morbid condition: more psychotropics prescribed! European Journal of General Practice: 2008, 14(1), 10-18

\begin{tabular}{|l|l|}
\hline Postprint Version & 1.0 \\
\hline Journal website & $\underline{\text { http://www.informaworld.com/smpp/content } \sim \mathrm{db}=\text { all?content=10.1080/1381478 }}$ \\
\cline { 2 - 2 } Pubmed link & $\underline{\underline{0701855724}}$ \\
\hline DOI & $10.1080 / 13814780701855724$ \\
\hline
\end{tabular}

This is a NIVEL certified Post Print, more info at http://www.nivel.eu

\title{
Depressed and a co-morbid condition: more psychotropics prescribed!
}

\author{
MirRian SMOLDERS ${ }^{\text {A }}$; MirANDA LAURANT ${ }^{\mathrm{A}}$; ERIC VAN RIJSWIJK ${ }^{\mathrm{B}}$; JAN MULDER ${ }^{\mathrm{A}}$; \\ Jozé BRASPENNING ${ }^{\mathrm{A}}$; Peter VERHAAK ${ }^{\mathrm{C}}$; MiCHEL WENSING ${ }^{\mathrm{A}}$; RiCHARD GROL ${ }^{\mathrm{A}}$ \\ a Centre for Quality of Care Research (WOK), \\ b Department of General Practice, Radboud University Nijmegen Medical Centre (RUNMC), \\ Nijmegen, the Netherlands \\ c Netherlands Institute for Health Services Research (NIVEL), Utrecht, the Netherlands
}

\begin{abstract}
Background: Depression often occurs simultaneously with a variety of somatic, psychiatric, and social conditions. Knowledge about differences in the pharmacological treatment of depressed patients with and without co-morbidity is lacking. Objective: To compare GPs' pharmacological treatment of depressed patients with and without co-morbidity. Methods: Data were extracted from the computerized medical records of 77 general practices participating in the Dutch National Information Network of General Practice (LINH). We used diagnosis and prescription data of newly diagnosed depressed patients aged 18-65 years ( $n=4372$ ). A mixed-model technique was used for analyzing the medical data. Results: During the year after diagnosing depression, depressed patients who also suffered from chronic somatic or psychiatric morbidity were prescribed more psychotropics than patients with depression only. Prescription patterns of psychotropic drugs for depressed patients with and without co-morbid social problems differed only during the first 3 months after diagnosis. For the whole 1-year period after diagnosis, the pharmacological treatment of depression in patients with and without co-morbid social problems did not differ. Conclusion: Our results indicate that chronic somatic or psychiatric co-morbidity in depressed patients leads to higher GP prescription levels of psychotropics, whereas co-morbid social problems do not seem to influence GPs' pharmacological treatment decisions for depression.
\end{abstract}

\section{INTRODUCTION}

Co-morbidity is a well-known phenomenon in depression, and it is widely agreed that the majority of depressive disorders do not present as a single condition 1, 2. Both clinical and epidemiological studies have documented that depression frequently occurs simultaneously with a variety of chronic somatic illnesses 3-5. In addition, research has shown an 
Smolders, M., Laurant, M., Rijswijk, E. van, Mulder, J., Braspenning, J., Verhaak, P., Wensing, M., Grol, R. Depressed and a co-morbid condition: more psychotropics prescribed! European Journal of General Practice: 2008, 14(1), 10-18

association with psychiatric disorders 6-8 as well as a relationship with psychiatric disorders and impairments in social functioning 9, 10. Depression responds to pharmacologic and behavioural treatments, both individually and in combination. It is crucial to treat depression effectively in patients with other problems, because depression increases patients' sensitivity to somatic distress, leads to poorer self-care, and worsens the prognosis associated with disorders such as cardiovascular disease 11,12. Effective treatment of depression can have a positive influence on the course of co-morbid conditions and improves overall wellbeing 13.

Previous studies have shown that patients with a diagnosis of major depression have a higher risk of not being diagnosed as depressed by GPs if they have additional somatic illness(es) 14-18. In contrast, the co-occurrence of major depression and anxiety has been found to facilitate recognition of depression 19. There are several reasons to suspect that, in addition to differences in diagnosing depression in patients with and without co-morbid conditions, there are also differences in GPs' pharmacological treatment of depression in patients with and without co-morbidity. First, somatic co-morbid conditions may complicate GPs' treatment decisions about depression. In the depressed patient with somatic comorbidity, the GP must develop a pharmacologic approach that will be effective and yet have a favourable side-effect profile relative to the patient's other conditions and treatments.

Conversely, the co-occurrence of depression and other psychiatric morbidity may provide GPs more opportunities to treat patients with psychotropics. A recent study reported that treatment with psychotropic drugs is offered more frequently to patients with a combined depressive and anxiety disorder, compared with patients diagnosed with depression only 20. Little is known about whether and how other psychiatric conditions actually influence GPs' pharmacological treatment of depression. According to the very few existing studies on the influence of coexisting psychosocial problems on the pharmacological treatment of depression, patients with a depressive disorder and concurrent psychosocial problems proved to be more likely to receive prescriptions for benzodiazepines and less likely for antidepressants compared to patients with a unimorbid depressive disorder 21, 22.

Our study was designed to compare the pharmacological treatment patterns of depression in general practice patients with and without concurrent chronic somatic, psychiatric, or social morbidity. The results could reveal insight into the prescription behaviour of GPs treating depressed patients with and without co-morbidity. This insight could serve as a trigger for quality-improvement activities and provides valuable information on where to target qualityimprovement efforts with respect to the medical treatment of depression. We hypothesized: 1) that depressed patients with co-morbid chronic somatic conditions are prescribed fewer antidepressants and benzodiazepines than patients with a single diagnosis of depression; 2) that depressed patients with other co-morbid psychiatric conditions are prescribed more antidepressants and benzodiazepines than patients with a single diagnosis of depression; and 3 ) that depressed patients with co-morbid social problems are prescribed fewer antidepressants, but more benzodiazepines than patients with a single diagnosis of depression.

\section{METHODS}

\section{Setting and study population}

The study population for this cohort study was identified within a national representative computerized GP-based network in the Netherlands, i.e., the National Information Network of General Practice (LINH) 23. In this network, GP staff are trained to use International Classification of Primary Care (ICPC) codes 24 and routinely record encoded patient information using a computerized medical record system. To ensure completeness of data, participating practices must have a (nearly) paperless office. Within this network, data are continuously extracted twice a year from the computerized medical records used in the practices to file patient information. 
Smolders, M., Laurant, M., Rijswijk, E. van, Mulder, J., Braspenning, J., Verhaak, P., Wensing, M., Grol, R. Depressed and a co-morbid condition: more psychotropics prescribed! European Journal of General Practice: 2008, 14(1), 10-18

Practices were selected according to the availability of reliable and valid data on diagnoses and prescriptions in the database in the years 2001-2003 ( $n=119)$. Practices that did not have complete data as well as practices that did not have data for a period of 16 consecutive months were excluded. The maximum allowable period of missing data was 4 weeks.

\section{Procedure and data collection}

GPs routinely recorded diagnostic information and therapeutic actions according to the ICPC, and medical drug prescriptions according to the Anatomical Therapeutic Chemical (ATC) Classification System 25. Data concerning diagnostic information and the pharmacological treatment of depression were extracted from the electronic patient records at patient level using specially developed software. These data included ICPC codes of a number of chronic somatic conditions (as classified by Statistics Netherlands), psychiatric conditions, and social conditions, as well as prescriptions with ATC codes for antidepressants and benzodiazepines. Box 1 contains the selected ICPC codes and ATC codes included in this study. The pharmacological treatment of depression was followed for 1 year after diagnosing a new episode of depression by the GP.

\section{[BOX 1]}

\section{Measures}

In the ICPC, two codes deal with depression: P76 (depressive disorder) and P03 (depressive feelings) 24. In our study, patients having an episode of P76 and/or P03 were considered to be diagnosed as depressed by their GP, while patients without such episodes were not. An episode of depression was considered as "new" if patients were not diagnosed by their GP as depressed during the preceding 4 months. A co-morbid condition was defined as having at least one diagnosed chronic somatic, psychiatric, or social condition in the 4 months preceding or the 4 months following the diagnosis of a new episode of depression. The presence of concurrent chronic somatic morbidity was determined on the basis of ICPC-coded diagnoses of chronic somatic conditions recorded by GPs. The following nine categories of chronic somatic morbidity were distinguished (Box 1): neurological conditions; musculoskeletal conditions; cardiovascular conditions; respiratory conditions; skin conditions; endocrine, metabolic, and nutritional conditions; digestive conditions; a category of malignant chronic somatic conditions; and a category of other non-malignant chronic somatic conditions.

The presence of concurrent psychiatric morbidity was determined on the basis of ICPCcoded diagnoses of mental or psychiatric conditions recorded by GPs. The following six categories of psychiatric morbidity were distinguished (Box 1): anxiety complaints/anxiety disorder; neurasthenia (i.e., either persistent and distressing feelings of exhaustion after minor mental effort, or persistent and distressing feelings of fatigue after minor physical effort) 26; acute stress reaction; sleep disturbance; drug abuse; and other mental symptom/complaint.

The presence of concurrent social morbidity was determined on the basis of ICPC-coded diagnoses of social conditions recorded by GPs. The following five categories of social morbidity were distinguished (Box 1): problem working conditions/problem with being unemployed; relation problem with partner/child/parent/other family member/friend; problem with partner/child/parent/other family member being ill; loss or death of partner/child/parent/other family member; and other social problem.

For the analysis regarding the psychotropics prescribed, we included only patients with mono-morbid pathology concerning the three subgroups of chronic somatic, psychiatric, or social morbidity. Within each of these three subgroups, patients could suffer from more conditions simultaneously. For example, depressed patients with cardiovascular morbidity (chronic somatic) as well as sleep disturbance (psychiatric) were excluded from our analysis, 
Smolders, M., Laurant, M., Rijswijk, E. van, Mulder, J., Braspenning, J., Verhaak, P., Wensing, M., Grol, R. Depressed and a co-morbid condition: more psychotropics prescribed! European Journal of General Practice: 2008, 14(1), 10-18

whereas depressed patients with cardiovascular morbidity as well as respiratory morbidity (both chronic somatic) were included in the analysis.

\section{Analysis}

First, we calculated the number of patients considered to have a new episode of depression. After that, we determined the incidence of depressive disorders with and without comorbidity. Finally, we calculated the number of depressed patients with and without comorbidity who received pharmacological treatment during the year after their depression diagnosis. A mixed model was conducted to compare the pharmacological treatment of depression in patients with and without concurrent chronic somatic, psychiatric, or social morbidity. Our model included correction for the possible effect of practice. The mixed model produced estimates of treatment means-referred to as "estimated mean number of prescriptions" - and standard errors of differences. We only used this model for the total subgroups of chronic somatic, psychiatric, or social co-morbidity. To show the changes in the levels of prescription of psychotropics over the course of the year after diagnosing depression, the year was divided into two periods: 0-3 months after depression diagnosis and 4-12 months after depression diagnosis. The number of psychotropic drug prescriptions was expressed as the estimated quarterly mean number of prescriptions per patient. SAS version 8.0 was used for the statistical analysis. Significance was accepted at the $5 \%$ level.

\section{RESULTS}

\section{Study population characteristics}

Seventy-seven practices met the inclusion criteria. From these 77 practices, a total number of 4372 newly diagnosed depressed patients aged 18-65 years were included. Table I illustrates the demographic and clinical characteristics of the 4372 patients with a newly diagnosed depression. The majority of the patients had a co-morbid condition. Chronic somatic conditions occurred most frequently simultaneously with depression. The most prevalent concurrent chronic somatic disease category was musculoskeletal. Anxiety was by far the most common concurrent psychiatric condition. Social conditions that occurred most frequently simultaneously with depression were relation problems and problems with (un)employment. About 20\% of the patients suffered from multiple concurrent conditions, including chronic somatic, psychiatric, and/or social co-morbidity. These patients were excluded from the analysis. Finally, 3488 patients were included in the analysis of psychotropic drug prescription. During the year after diagnosing depression, $67.1 \%$ of the depressed patients with no co-morbidity were prescribed an antidepressant, and $23.8 \%$ of this patient group received a benzodiazepine prescription. Regarding the patients who suffered from depression and a co-morbid condition simultaneously, these percentages were $73.7 \%$ and $42.2 \%$, respectively.

\section{[TABLE 1]}

\section{Course of pharmacological treatment for depressed patients with and without multimorbidity}

Tables II-IV show the mixed-model estimates of quarterly mean number of antidepressant and benzodiazepine prescriptions per patient for patients with and without co-morbidity. Most antidepressants and benzodiazepines for both depressed patients with and without a comorbid condition were prescribed in the first months after their depression diagnosis. In the following 9 months, the prescription rate of psychotropics declined considerably for all subgroups 
Smolders, M., Laurant, M., Rijswijk, E. van, Mulder, J., Braspenning, J., Verhaak, P., Wensing, M., Grol, R. Depressed and a co-morbid condition: more psychotropics prescribed! European Journal of General Practice: 2008, 14(1), 10-18

\section{[TABLE 2]}

\section{Prescription of psychotropics for depression and concurrent chronic somatic conditions}

Table II presents the estimated mean number of antidepressant and benzodiazepine prescriptions for depressed patients with and without concurrent chronic somatic morbidity. During the first months after diagnosing depression, the prescription rate of antidepressants for patients with a single diagnosis of depression hardly differed from that of depressed patients with a chronic somatic co-morbid condition. In the following 9 months, however, depressed patients who suffered simultaneously from chronic somatic morbidity were prescribed more antidepressants than patients with depression only. During the year after their diagnosis of depression, patients who suffered from concurrent chronic somatic conditions received almost twice as many prescriptions for benzodiazepines than patients with depression only.

Regarding specific categories of concurrent chronic somatic conditions, depressed patients who suffered simultaneously from neurological morbidity were prescribed markedly more antidepressants during the first months after their depression diagnosis than patients with depression only. All subgroups with depression and a concurrent chronic somatic condition, except that with endocrine/metabolic/nutritional morbidity, received considerably more benzodiazepine prescriptions during the first months after their depression diagnosis than patients with depression only.

\section{Prescription of psychotropics for depression and concurrent other psychiatric conditions}

Table III presents the estimated mean number of antidepressant and benzodiazepine prescriptions for depressed patients with and without concurrent other psychiatric morbidity. During the year after their diagnosis of depression, patients who suffered from concurrent other psychiatric conditions were prescribed more antidepressants as well as more benzodiazepines than patients with depression only. The prescription rate of benzodiazepines for depressed patients with concurrent other psychiatric morbidity was three times higher than that of patients with a single diagnosis of depression. The higher prescription rate of psychotropic agents for patients with depression and a concurrent other psychiatric condition was observable in all our subgroups. Even though the prescription rate of benzodiazepines declined during the course of the year, it remained high.

\section{[TABLE 3]}

\section{Prescription of psychotropics for depression and concurrent social conditions}

Table IV presents the estimated mean number of antidepressant and benzodiazepine prescriptions for depressed patients with and without concurrent social problems. In the quarter after diagnosing depression, patients with concurrent social problems received more benzodiazepine prescriptions, but no more antidepressant prescriptions than patients with depression only. In the following 9 months, neither the prescription level of benzodiazepines nor the prescription level of antidepressants differed for depressed patients with and without co-morbid social problems.

Regarding specific subgroups, it was mainly depressed patients who had a concurrent problem because of a family member being ill or a problem belonging to the category "other social problem" who received many antidepressant prescriptions during the first months after diagnosing depression. In particular, depressed patients with problem working conditions, relation problems, or problems due to loss or death of a family member were prescribed considerably more benzodiazepines in this period, compared to patients with a single diagnosis of depression. The prescription rate of benzodiazepines for depressed patients who suffered simultaneously from problems due to loss or death of a family member remained 
Smolders, M., Laurant, M., Rijswijk, E. van, Mulder, J., Braspenning, J., Verhaak, P., Wensing, M., Grol, R. Depressed and a co-morbid condition: more psychotropics prescribed! European Journal of General Practice: 2008, 14(1), 10-18

remarkably high in the following 9 months. They received more than three times as many prescriptions for benzodiazepines than patients with depression only.

\section{[TABLE 4]}

\section{DISCUSSION}

\section{Summary of main findings and comparison with existing literature}

Our first hypothesis, that the presence of chronic somatic morbidity in depressed patients is a complicating factor in the pharmacological treatment of depression leading to the prescription of less psychotropic medication by GPs, proved to be incorrect. The opposite appeared to be true: patients with concurrent chronic somatic conditions received more prescriptions for both antidepressants and benzodiazepines than patients with depression only. In contrast to our findings, two previous studies have suggested that there is no difference in pharmacologic depression treatment of medically ill and non-medically ill patients 27, 28. However, none of these studies were carried out in a general practice setting. This study also found that depressed patients who suffered simultaneously from other psychiatric morbidity were prescribed both more antidepressants and more benzodiazepines than patients with a single diagnosis of depression. These results are consistent with our second hypothesis. Furthermore, these more robust results confirmed earlier findings that patients with mixed depression and anxiety received more prescriptions for psychotropic drugs 20. An explanation of the observed difference in GPs' pharmacological treatment patterns for depressed patients with and without chronic somatic or psychiatric co-morbidity may be that GPs have higher contact rates with patients who suffer from multimorbidity, and thus have more opportunities to treat their depression.

In addition, we found that the pharmacological treatment of depressed patients with and without social problems differed only during the first 3 months after diagnosis: depressed patients with concurrent social problems were prescribed more benzodiazepines, but no more antidepressants than patients with a single diagnosis of depression. From a case-control study, the presence of concurrent psychosocial problems seemed to have an influence on psychotropic prescription by GPs for patients with depression 21 . Our data only partly support these findings.

Finally, our results showed that the prescription rate of benzodiazepines remained high throughout the year after diagnosing depression.

\section{Strengths and limitations of the study}

The main strength of this study was our ability to examine a national representative sample of primary care practices and patients, and to explore, in a longitudinal way, an important healthcare issue in primary care. The findings of our study are likely to be generalizable to other settings and countries.

Our findings depend on the quality of registration by the GPs. Participating GPs were experienced in working with electronic medical records and with ICPC. While there is no gold-standard measure for assessing depression and a comprehensive range of concurrent conditions, the validity of assessments is enhanced given that our findings correspond reasonably well to other studies in terms of the proportion of patients diagnosed with a particular condition or disease 29, 30.

It is possible that a few concurrent conditions, e.g., headaches and sleep problems, may be a developmental precursor to depression or simply reflect complaints arising purely from depression. Therefore, it cannot be ruled out that some patients with depression only were incorrectly assigned to one of the subgroups with concurrent conditions.

In accordance with reality, the diagnostic subgroups in our study were not mutually exclusive. Although thorough analysis of the overlap did not reveal a strong degree of 
Smolders, M., Laurant, M., Rijswijk, E. van, Mulder, J., Braspenning, J., Verhaak, P., Wensing, M., Grol, R. Depressed and a co-morbid condition: more psychotropics prescribed! European Journal of General Practice: 2008, 14(1), 10-18

overlap between two or more specific subgroups, the precise influence of overlapping subgroups is not known.

\section{Implications for clinical practice and future research}

It is encouraging that GPs do not ignore the pharmacological treatment of depression in their patients who also suffer from concurrent somatic morbidity. This is of crucial clinical importance because appropriate treatment of depression can reduce both the patient and socioeconomic burden that is associated with multimorbidity 5,13 .

Although it was not the primary aim of this study to assess adherence to guidelines by GPs, there were some indications that psychotropic drug treatment was not always conducted in accordance with treatment recommendations 31. The significantly higher prescription rate of both antidepressants and benzodiazepines for depressed patients with a co-morbid chronic somatic condition was inappropriate and unsuitable. In addition, all our study groups received long-term prescriptions for benzodiazepines. Evidence-based guidelines advise against long-term prescriptions of benzodiazepines, because long-term benzodiazepine use appears to provoke more severe adverse effects, including memory impairment, tolerance, and dependence. Benzodiazepines are only considered to be effective for a limited period of time 31, 32. Given the lack of effectiveness and potential hazards of (long-term) use of psychotropic drugs, GPs should be cautious in prescribing these drugs, especially in the long term.

According to the guidelines published by the Dutch College of General Practitioners (NHG) 31, both pharmacologic and non-pharmacologic therapy may be considered appropriate depression treatment. To complement our findings, future research could examine GPs' non-pharmacologic management of depression with and without co-morbidity, and subsequently make a comparison between depression care delivered and care recommended in guidelines on depression.

\section{ACKNOWLEDGEMENTS}

This study was funded by a grant from the National Association of General Practitioners (LHV). However, the views expressed here are those of the authors and not necessarily those of the funding body. Competing interests: none declared.

\section{REFERENCES}

1. Wittchen, HU, Knauper, B. and Kessler, RC. (1994) Lifetime risk of depression. Br J Psychiatry Suppl 26 , pp. 16-22.

2. Wittchen, HU. (1996) Critical issues in the evaluation of comorbidity of psychiatric disorders. Br J Psychiatry Suppl 30 , pp. 9-16.

3. Gagnon, LM and Patten, SB. (2002) Major depression and its association with long-term medical conditions. Can J Psychiatry 47 , pp. 149-152.

4. Moldin, SO, Scheftner, WA, Rice, JP, Nelson, E., Knesevich, MA and Akiskal, H. (1993) Association between major depressive disorder and physical illness. Psychol Med 23, pp. 755-761.

5. Wittchen, HU, Lieb, R., Wunderlich, U. and Schuster, P. (1999) Comorbidity in primary care: presentation and consequences. J Clin Psychiatry 60:Suppl 7 , pp. 29-36.

6. de Graaf, R., Bijl, RV, Spijker, J., Beekman, AT and Vollebergh, WA. (2003) Temporal sequencing of lifetime mood disorders in relation to comorbid anxiety and substance use disorders-findings from the Netherlands Mental Health Survey and Incidence Study. Soc Psychiatry Psychiatr Epidemiol 38 , pp. 1-11. ]

7. Kessler, RC, Nelson, CB, McGonagle, KA, Liu, J., Swartz, M. and Blazer, DG. (1996) Comorbidity of DSM-III-R major depressive disorder in the general population: results from the US National Comorbidity Survey. Br J Psychiatry Suppl 30 , pp. 17-30.

8. Merikangas, KR, Angst, J., Eaton, W., Canino, G., Rubio Stipec, M and Wacker, H. (1996) Comorbidity and boundaries of affective disorders with anxiety disorders and 
Smolders, M., Laurant, M., Rijswijk, E. van, Mulder, J., Braspenning, J., Verhaak, P., Wensing, M., Grol, R. Depressed and a co-morbid condition: more psychotropics prescribed! European Journal of General Practice: 2008, 14(1), 10-18

substance misuse: results of an international task force. Br J Psychiatry Suppl 30 , pp. 5867.

9. Ormel, J., VonKorff, M., Ustun, TB, Pini, S., Korten, A. and Oldehinkel, T. (1994) Common mental disorders and disability across cultures. Results from the WHO Collaborative Study on Psychological Problems in General Health Care. JAMA 272 , pp. 1741-1748.

10. Rodriguez, BF, Bruce, SE, Pagano, ME and Keller, MB. (2005) Relationships among psychosocial functioning, diagnostic comorbidity, and the recurrence of generalized anxiety disorder, panic disorder, and major depression. J Anxiety Disord 19 , pp. 752-766.

11. Katon, W., Kleinman, A. and Rosen, G. (1982) Depression and somatization: a review. Part II. Am J Med 72 , pp. 241-247.

12. Musselman, DL and Nemeroff, CB. (2000) Depression really does hurt your heart: stress, depression, and cardiovascular disease. Prog Brain Res 122 , pp. 43-59.

13. Simon, GE, Katon, W., Rutter, C., VonKorff, M., Lin, E. and Robinson, P. (1998) Impact of improved depression treatment in primary care on daily functioning and disability. Psychol Med 28 , pp. 693-701.

14. Coulehan, JL, Schulberg, HC, Block, MR, Janosky, JE and Arena, VC. (1990) Medical comorbidity of major depressive disorder in a primary medical practice. Arch Intern Med 150 , pp. 2363-2367.

15. Freeling, P., Rao, BM, Paykel, ES, Sireling, LI and Burton, RH. (1985) Unrecognised depression in general practice. Br Med J (Clin Res Ed) 290 , pp. 1880-1883.16. Sartorius, N., Ustun, TB, Lecrubier, Y. and Wittchen, HU. (1996) Depression comorbid with anxiety: results from the WHO study on psychological disorders in primary health care. $\mathrm{Br} \mathrm{J}$ Psychiatry Suppl 30 , pp. 38-43.

17. Tylee, A., Freeling, P., Kerry, S. and Burns, T. (1995) How does the content of consultations affect the recognition by general practitioners of major depression in women?. Br J Gen Pract 45 , pp. 575-578.

18. Tylee, AT, Freeling, P. and Kerry, S. (1993) Why do general practitioners recognize major depression in one woman patient yet miss it in another?. Br J Gen Pract 43, pp. 327-330.

19. Coyne, JC, Schwenk, TL and Fechner Bates, S. (1995) Nondetection of depression by primary care physicians reconsidered. Gen Hosp Psychiatry 17 , pp. 3-12.

20. van Rijswijk, E., Borghuis, M., van De Lisdonk, E., Zitman, F. and van Weel, C. (2007) Treatment of mental health problems in general practice: a survey of psychotropics prescribed and other treatments provided. Int J Clin Pharmacol Ther 45, pp. 23-29.

21. van Rijswijk, E., Lucassen, P., van De Lisdonk, E., Zitman, F. and van Weel, C. (2006) Do co-existing psychosocial problems influence the prescription of psychotropic medication in depressive and anxiety disorders?. Eur J Gen Pract 12 , pp. 37-39.

22. van Rijswijk, E., van Hout, H., van De Lisdonk, E., Zitman, F. and van Weel, C. Barriers in recognising, diagnosing and managing depressive and anxiety disorders as experienced by GPs: a focus group study. - Submitted 2007

23. Verheij, R., Jabaaij, L. and De Bakker, D. (2002) Cijfers uit het Landelijk Informatie Netwerk Huisartsenzorg: contacten, verwijzingen en voorschrijven in de huisartspraktijk. [LINH annual report 2001: figures from the Dutch continuous morbidity registration network in general practice: encounters, referrals, and prescriptions in general practice.] Utrecht, Nijmegen: LHV, NHG, NIVEL, WOK;

24. Lamberts, H. and Wood, M. (1990) International classification of primary care (ICPC) Oxford University Press, Oxford

25. (1996) WHO/NCM , Oslo - 1st edition

26. Hickie, I., Davenport, T., Issakidis, C. and Andrews, G. (2002) Neurasthenia: prevalence, disability and health care characteristics in the Australian community. $\mathrm{Br} \mathrm{J}$ Psychiatry 181 , pp. 56-61.

27. Koike, AK, Unutzer, J. and Wells, KB. (2002) Improving the care for depression in patients with comorbid medical illness. Am J Psychiatry 159 , pp. 1738-1745.

28. Stockton, P., Gonzales, JJ, Stern, NP and Epstein, SA. (2004) Treatment patterns and outcomes of depressed medically ill and non-medically ill patients in community psychiatric practice. Gen Hosp Psychiatry 26 , pp. 2-8. 
Smolders, M., Laurant, M., Rijswijk, E. van, Mulder, J., Braspenning, J., Verhaak, P., Wensing, M., Grol, R. Depressed and a co-morbid condition: more psychotropics prescribed! European Journal of General Practice: 2008, 14(1), 10-18

29. Bijl, RV, Ravelli, A. and van Zessen, G. (1998) Prevalence of psychiatric disorder in the general population: results of the Netherlands Mental Health Survey and Incidence Study (NEMESIS). Soc Psychiatry Psychiatr Epidemiol 33 , pp. 587-595.

30. Nuyen, J., Volkers, AC, Verhaak, PF, Schellevis, FG, Groenewegen, PP and Van den Bos, GA. (2005) Accuracy of diagnosing depression in primary care: the impact of chronic somatic and psychiatric co-morbidity. Psychol Med 35 , pp. 1185-1195.

31. van Marwijk, HWJ, Grundmeijer, HGLM, Bijl, D., van Gelderen, MG, de Haan, M. and van Weel-Baumgarten, EM (2003) NHG-Standaard Depressieve Stoornis. Eerste

Herziening. Huisarts en Wetenschap 46 , pp. 614-623.

32. Furukawa, TA, Streiner, DL and Young, LT. (2001) Antidepressant plus benzodiazepine for major depression. Cochrane Database Syst Rev - CD001026

\section{BOX AND TABLES}

Box 1. International Classification of Primary Care Codes (ICPC) and Anatomical Therapeutic Chemical (ATC) codes used to identify patients and obtain insight into the pharmacological treatment of those patients.

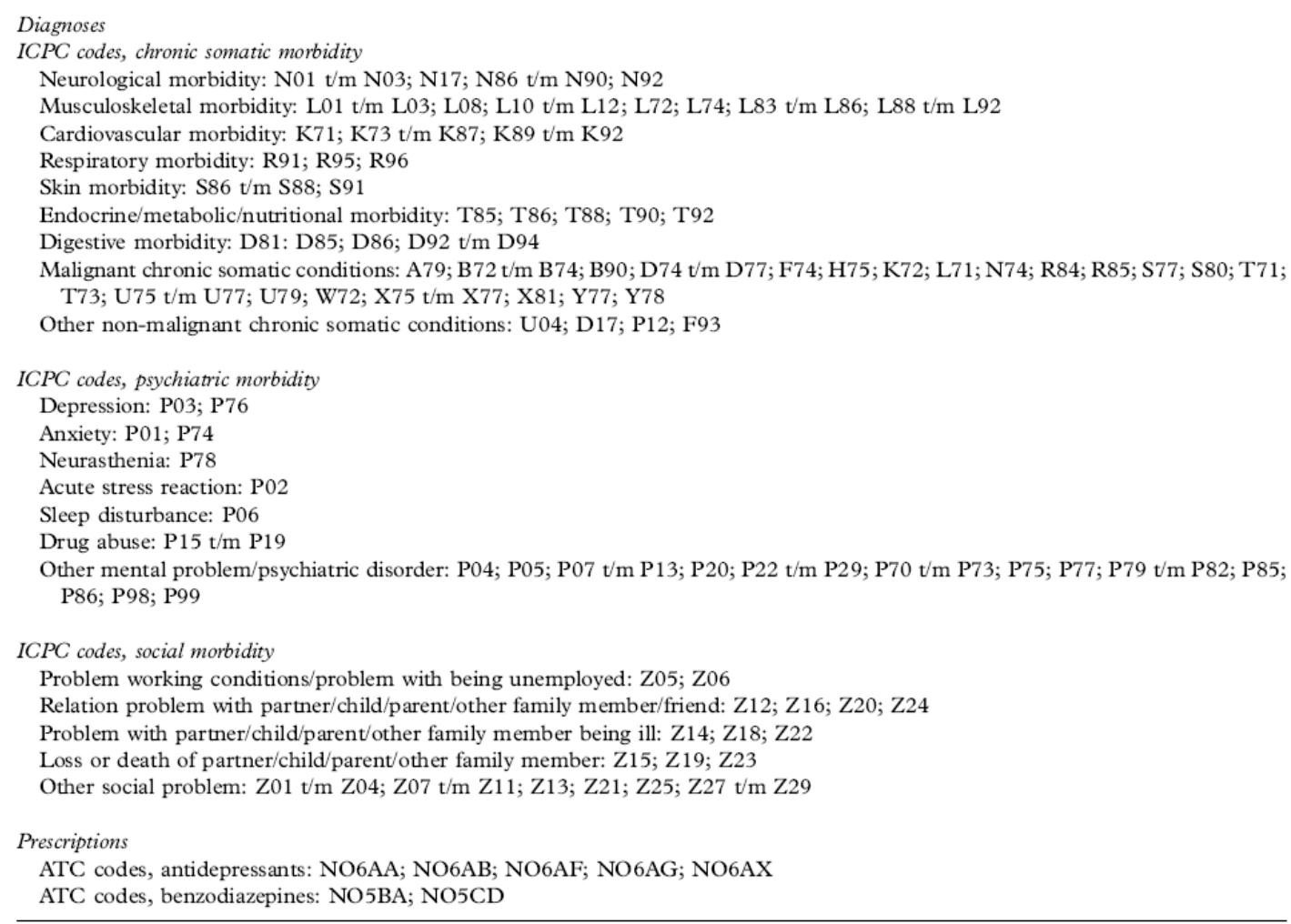


Smolders, M., Laurant, M., Rijswijk, E. van, Mulder, J., Braspenning, J., Verhaak, P., Wensing, M., Grol, R. Depressed and a co-morbid condition: more psychotropics prescribed! European Journal of General Practice: 2008, 14(1), 10-18

Table I. Characteristics of the depressed patients $(n=4372)$.

\begin{tabular}{|c|c|}
\hline Mean age, years (SD) & $41.4(11.7)$ \\
\hline \multicolumn{2}{|l|}{ Gender } \\
\hline Female & $2813(64.3 \%)$ \\
\hline Male & $1559(35.7 \%)$ \\
\hline No co-morbidity & $1686(38.6 \%)$ \\
\hline \multicolumn{2}{|l|}{ Subgroups of co-morbidity ${ }^{\mathrm{a}}$} \\
\hline Concurrent chronic somatic conditions & $1768(40.4 \%)$ \\
\hline Concurrent psychiatric conditions & $1319(30.2 \%)$ \\
\hline Concurrent social conditions & $480(11.0 \%)$ \\
\hline \multicolumn{2}{|l|}{ Categories of chronic somatic conditions $\mathrm{s}^{\mathrm{a}}$} \\
\hline Musculoskeletal & $897(20.5 \%)$ \\
\hline Cardiovascular & $401(9.2 \%)$ \\
\hline Neurological & $350(8.0 \%)$ \\
\hline Skin & $255(5.8 \%)$ \\
\hline Endocrine/metabolic/nutritional & $152(3.5 \%)$ \\
\hline Respiratory & $118(2.7 \%)$ \\
\hline Digestive & $84(1.9 \%)$ \\
\hline Malignant chronic somatic conditions & $35(0.8 \%)$ \\
\hline Other non-malignant chronic somatic conditions & $33(0.8 \%)$ \\
\hline \multicolumn{2}{|l|}{ Categories of psychiatric conditions $\mathrm{s}^{\mathrm{b}}$} \\
\hline Anxiety & $487(11.1 \%)$ \\
\hline Sleep disturbance & $282(6.4 \%)$ \\
\hline Neurasthenia & $227(5.2 \%)$ \\
\hline Acute stress reaction & $163(3.7 \%)$ \\
\hline Drug abuse & $123(2.8 \%)$ \\
\hline Other mental problem/psychiatric disorder & $306(7.0 \%)$ \\
\hline \multicolumn{2}{|l|}{ Categories of social conditions ${ }^{b}$} \\
\hline Relation problem with partner/child/parent/other family member/friend & $150(3.4 \%)$ \\
\hline Problem working conditions/problem with being unemployed & $145(3.3 \%)$ \\
\hline Loss or death of partner/child/parent/other family member & $75(1.7 \%)$ \\
\hline Problem with partner/child/parent/other family member being ill & $56(1.3 \%)$ \\
\hline Other social problem & $99(2.3 \%)$ \\
\hline \multicolumn{2}{|l|}{ Pharmacological treatment of patients without co-morbid conditions $(n=1686)$} \\
\hline Antidepressant prescription during year after depression diagnosis & $1131(67.1 \%)$ \\
\hline Benzodiazepine prescription during year after depression diagnosis & $402(23.8 \%)$ \\
\hline \multicolumn{2}{|l|}{ Pharmacological treatment of patients with co-morbid conditions $(n=2686)$} \\
\hline Antidepressant prescription during year after depression diagnosis & $1979(73.7 \%)$ \\
\hline Benzodiazepine prescription during year after depression diagnosis & $1134(42.2 \%)$ \\
\hline
\end{tabular}

${ }^{\mathrm{a}}$ Within these subgroups, patients could suffer from multiple co-morbid conditions.

${ }^{b}$ Within these categories, patients could suffer from more conditions simultaneously.

Table III. Estimated quarterly mean number of prescriptions (and standard error) per patient with and without concurrent psychiatric morbidity.

\begin{tabular}{|c|c|c|c|c|c|}
\hline \multirow[b]{2}{*}{ Depression with: } & \multicolumn{2}{|c|}{$0-3$ months after diagnosis } & \multicolumn{2}{|c|}{ 4-12 months after diagnosis ${ }^{\mathrm{a}}$} & \multirow[b]{2}{*}{$n$} \\
\hline & Antidepressants & Benzodiazepines & Antidepressants & Benzodiazepines & \\
\hline No co-morbidity & $1.618(0.05)$ & $0.346(0.04)$ & $0.637(0.03)$ & $0.180(0.04)$ & 1686 \\
\hline Concurrent psychiatric morbidity & $2.361(0.09)^{\star \star}$ & $1.193(0.07)^{\star \star}$ & $0.956(0.05)^{\star \star}$ & $0.577(0.05)^{\star \star}$ & 531 \\
\hline Anxiety & 2.516 & 1.064 & 1.020 & 0.476 & 178 \\
\hline Neurasthenia & 2.036 & 0.580 & 0.679 & 0.205 & 144 \\
\hline Acute stress reaction & 2.171 & 0.973 & 0.839 & 0.408 & 86 \\
\hline Sleep disturbance & 2.229 & 1.296 & 0.834 & 0.713 & 139 \\
\hline Drug abuse & 1.990 & 1.293 & 0.941 & 1.094 & 73 \\
\hline Other mental problem/psychiatric disorder & 1.593 & 0.689 & 0.750 & 0.306 & 184 \\
\hline
\end{tabular}

${ }^{\mathrm{a}}$ Mean of second, third, and fourth quarter after depression diagnosis.

${ }^{\star \star} p<0.01$ compared to patients with no co-morbidity (mixed model only applied on total subgroup of psychiatric morbidity). 
Smolders, M., Laurant, M., Rijswijk, E. van, Mulder, J., Braspenning, J., Verhaak, P., Wensing, M., Grol, R. Depressed and a co-morbid condition: more psychotropics prescribed! European Journal of General Practice: 2008, 14(1), 10-18

Table IV. Estimated quarterly mean number of prescriptions (and standard error) per patient with and without concurrent social morbidity.

\begin{tabular}{|c|c|c|c|c|c|}
\hline \multirow[b]{2}{*}{ Depression with: } & \multicolumn{2}{|c|}{ 0-3 months after diagnosis } & \multicolumn{2}{|c|}{ 4-12 months after diagnosis ${ }^{\mathrm{a}}$} & \multirow[b]{2}{*}{$n$} \\
\hline & Antidepressants & Benzodiazepines & Antidepressants & Benzodiazepines & \\
\hline No co-morbidity & $1.618(0.05)$ & $0.346(0.04)$ & $0.637(0.03)$ & $0.180(0.04)$ & 1686 \\
\hline Concurrent social morbidity & $1.907(0.12)$ & $0.572(0.09)^{\star}$ & $0.666(0.07)$ & $0.242(0.06)$ & 197 \\
\hline $\begin{array}{l}\text { Problem working conditions/problem with being } \\
\text { unemployed }\end{array}$ & 1.749 & 0.690 & 0.615 & 0.210 & 145 \\
\hline $\begin{array}{l}\text { Relation problem with partner/child/parent/other } \\
\text { family member/friend }\end{array}$ & 1.905 & 0.695 & 0.619 & 0.370 & 78 \\
\hline $\begin{array}{l}\text { Problem with partner/child/parent/other family } \\
\text { member being ill }\end{array}$ & 2.061 & 0.504 & 0.723 & 0.147 & 25 \\
\hline $\begin{array}{l}\text { Loss or death of partner/child/parent/other family } \\
\text { member }\end{array}$ & 1.587 & 0.698 & 0.695 & 0.655 & 44 \\
\hline Other social problem & 2.218 & 0.362 & 0.912 & 0.271 & 42 \\
\hline
\end{tabular}

${ }^{\mathrm{a}}$ Mean of second, third, and fourth quarter after depression diagnosis.

${ }^{\star} p<0.05$ compared to patients with no co-morbidity (mixed model only applied on total subgroup of social morbidity). 